\title{
A Case of Congenital Cystic Adenomatoid Malformation in a 10 Years Old Boy
}

\author{
AK Saha ${ }^{1}$, SA Fattah ${ }^{2}$, SS Parvin ${ }^{3}$, MM Hossain $^{4}$, BK Biswas $^{5}$
}

\begin{abstract}
:
Congenital Cystic Adenomatoid Malformation (CCAM) is a relatively rare congenital pulmonary cystic disease. By ultrasonography prenatal diagnosis can be made and most baby born without complication. Some babies need surgery at the first year of life for recurrent respiratory tract infection. Here a case of CCAM in a 10 year old boy is reported who presented with recurrent respiratory tract infection and underwent surgical resection successfully.
\end{abstract}

Key words: CCAM, hamartomatous malformation,amniocentesis.

\section{Introduction :}

Congenital Cystic Adenomatoid Malformation (CCAM) is a benign mass of lung tissue with an incidence of 1 in 25000-35000 ${ }^{1}$. It was called 'Congenital Bronchiectasis' or 'Pulmonary Cystic Disease' in older literature ${ }^{2}$. In this disorder a part or whole of a lobe or rarely an entire lung is replaced by a nonfunctioning cystic mass of abnormal lung tissue. The underlying cause is unknown but it may be regarded as a hamartomatous tissue resulting from developmental anomaly of both the tracheobronchial tree and the lung parenchyma. Depending on the gross appearance, CCAM may be classified into three categories $^{3}$. Type-1 has large $(>2 \mathrm{~cm})$ multiloculated cysts. Type- 2 has smaller uniform cysts, may be associated with other congenital anomalies and carries poor prognosis. Type-3 lesion is relatively solid with

1. Dr. Aloke Kumar Saha, MBBS, FCPS (Paediatrics), Assistant Professor, Department of Paediatrics, Faridpur Medical College, Faridpur.

2. Dr. Sk Abdul Fattah, MBBS, DTCD, FCPS (Medicine), Associate Professor, Department of Medicine, Faridpur Medical College, Faridpur.

3. Dr. Salma Shahnawas Parvin, MBBS, MD, (Radiology) Assistant Professor, Department of Radiology \& Imaging, Faridpur Medical College, Faridpur.

4. Dr. Md. Monowar Hossen, MBBS, DCH, Assistant Register, Department of Paediatrics, Faridpur Medical College, Faridpur.

5. Dr.Barun Kanti Biswas, MBBS, FCPS (Paediatrics), Associate Professor, Department of Paediatrics, Faridpur Medical College, Faridpur.

Address of correspondence :

Dr. Aloke Kumar Saha, MBBS, FCPS (Paediatrics), Assistant Professor, Department of Paediatrics, Faridpur Medical College, Faridpur. Mobile Phone: +8801711806903, Email: dralokeped@gmail.com brochiole-like structure and carries the worst prognosis. Most babies with CCAM are born without complication, may have surgery in the first year of life due to risk of recurrent lung infection ${ }^{4}$. Some CCAM patients live a normal life without any complication. Here a case of CCAM is reported in a 10 years old boy who presented with recurrent respiratory tract infection.

\section{Case history:}

A 10 years old boy weighing $20 \mathrm{~kg}$, son of nonconsanguineous parents, duely immunized, hailing from a middle class family of Pangsha, Rajbari presented with the complaints of cough for 10 days. Cough was nonproductive becoming intense in lying position and associated with breathlessness and tightness of the chest. Since last 6 days he also had been suffering from lowgrade intermittent fever not associated with chills, rigor, rash or convulsion. He had repeated attacks of cough and breathlessness since his 7 months of age. He used to take antibiotics and bronchodilators that gave him some temporary relief only to recur the symptoms after few days. He had no history of hemoptysis or contact with any tuberculosis patient. Physical examination revealed the patient ill looking with poor bodybuild, reduced movement of the right chest, tracheal shifting to the left, decreased vocal fremitus and stony dull percussion note over the right chest. On auscultation breath sound and vocal resonance were diminished with presence of coarse crepitations over the right chest. 
Investigation revealed mild anemia and leucocytocis. Chest X-ray (PA view) showed consolidation involving right mid and lower zone (Figure 1). CT scan showed large well defined capsulated cystic lesion occupying right lower lobe (Figure 2).

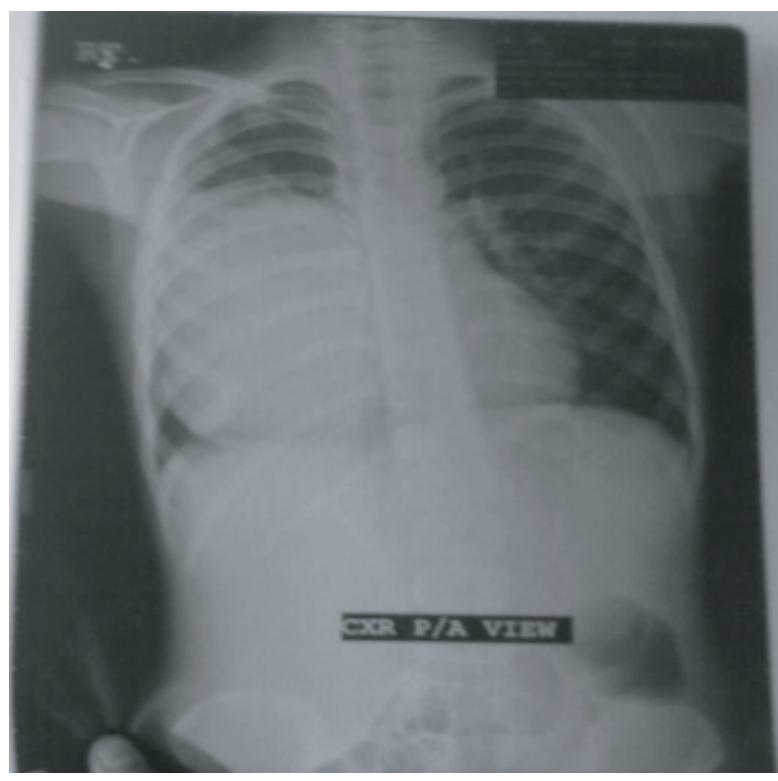

Figure-I: X-ray chest (P-A view) shows consolidation involving right mid \& lower zone

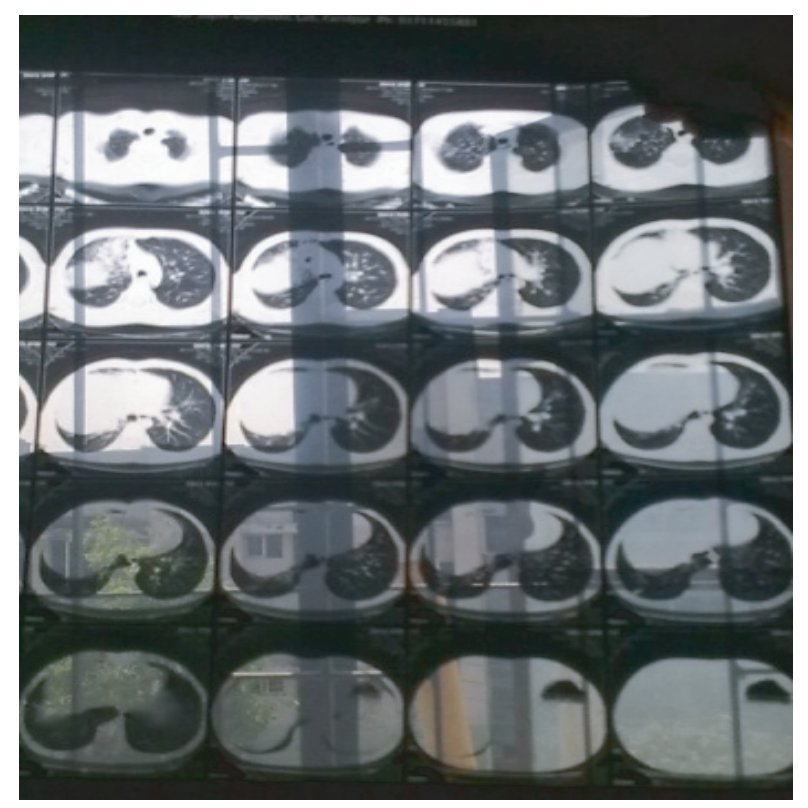

Figure-2: CT scan shows large well defined capsulated cystic lesion occupying right lower lobe.

\section{Discussion:}

CCAM is caused by overgrowth of abnormal lung tissue that may form fluid-filled cysts. The cysts prevent the tissue from functioning as normal lung tissue. CCAM may be detected by prenatal ultrasonography. Doctors should see the location and the size of the growth. The fetal heart may be shifted to the opposite side and normal lung tissue may be difficult to see on the side where the mass is located. MRI or CT scan may also be used to detect the mass ${ }^{5}$.

In most cases the fetus will do well and mother will carry the baby to term without any problem ${ }^{6}$. The mass may appear smaller or unchanged by serial ultrasonography between 28-30th weeks of pregnancy. It may shrink, even may disappear during the 3rd trimester of pregnancy ${ }^{7}$. However in small number of cases the mass may grow enormously to be life threatening for the fetus. It may compress bloodvessel making heart to pump harder leading to heart failure and hydrops foetalis. So, prenatal intervention should be done before the fetus develops hydrops. Fetal interventions include thoracocentesis or cystoamniotic shunts and for mother, therapeutic amniocentesis for polyhydramnios. Prenatal treatment with Betamethasone may reduce the size of the lesion and resolve hydrops fetalis. Close attention should be paid to mother's health, as mother may show symptoms of pre-eclampsia as the fetus develops hydrops. If the mother is ill and hydrops get too severe, it may not be possible to perform surgery. So intervention should be done before the fetus develops hydrops.

All babies with CCAM should be delivered in a hospital with neonatal ICU facility. Often babies born with no symptom at birth. If baby has no symptom and no prenatal intervention done, surgery may be performed at the age of 3-6 months.Babies with prenatal or postnatal surgical intervention continue to grow the lung upto the age of 9 years till the development of normal healthy lung.

\section{References :}

1. Laberge JM, Flageole H, Pugash $\mathrm{H}$ et al. Outcome of the prenatally diagnosed congenital cystic Adenomatoid lung malformation: a Canadian Experience. Fetal DiagnTher. 2001;16(3):178-86.

2. Seaton D, Seaton A. Developmental disorders of the lung. In:Seaton A, Seaton D, Leitch AD, editors.Crofton and Douglas's Respiratory Diseases. 5thed. Oxford:Blackwell Science;2000.p.1326.

3. Green TO, Finder JD. Congenital Disorders of the Lung. In:Behrman, Kliegman, Jenson, editors. Nelson Textbook of Pediatrics. 7thed. Philadelphia:Saunders;2004.p.1426.

4.Lyman K, Bosque K, Mirapeix TM, Marco MT, Asensio O, Domingo C. Late onset congenital cystic adenomatoid malformation of the lung. Embryology, clinical symptomatology, diagnostic procedures, therapeutic approach and clinical followup. Respiration. 2002; 69(2):148-54

5.Adcock ND, Harrison MR, Crombleholme TM et al. Fetal lung lesions: management and outcome. AM J Obstetric Gynecol. 1998; 179:884-9.

6. Gillivery M, Harrison MR, Goldstein TV, Adzick ND etal. Disappearing fetal lung lesions. I Pediatric Surg.1993; 28:1321-24.

7. Van LK, Teitelbaum DH, Hirschl TV, et al. Prenatal diagnosis of congenital cystic adenomatoid malformation and its potential presentation, surgical indications and natural history. J Pediatric Surg.1999;34:794-8. 